\title{
Relative Effectiveness of C Primary Afferent Fibers of Different Origins in Evoking a Prolonged Facilitation of the Flexor Reflex in the Rat
}

\author{
Clifford J. Woolf and Patrick D. Wall \\ Cerebral Functions Research Group, Department of Anatomy, University College London, London, United Kingdom
}

Changes in the excitability of the hamstring flexor withdrawal reflex produced by conditioning stimuli applied to $C$-afferent fibers of different origins have been examined in the decerebrate spinal rat. In the absence of conditioning stimuli, the flexor reflex elicited by a standard suprathreshold mechanical stimulus to the toes is stable when tested repeatedly for hours. Three categories of conditioning stimuli have been used in an attempt to modify the excitability of the flexor reflex; electrical stimulation of a cutaneous (sural) nerve or a muscle (gastrocnemiussoleus) nerve at $\mathrm{C}$-fiber strength; the application of mustard oil, a chemical irritant that activates chemosensitive $\mathrm{C}$-afferents, to the skin or injected intramuscularly and intraarticularly; and the indirect activation of high-threshold muscle afferents by fused tetanic contractions of the tibial muscles. Conditioning stimuli of an intensity sufficient to activate $\mathrm{C}$-afferent fibers result in a heterosynaptic facilitation of the flexor motoneuronal response to the standard test input, which lasts from $3 \mathrm{~min}$ to more than $3 \mathrm{hr}$, depending on the stimulus and the $\mathrm{C}$-afferents activated. Pretreatment of the sciatic nerve with the $\mathrm{C}$-fiber neurotoxin capsaicin abolishes all the postconditioning facilitations, which is an indication that it is likely that it is C-afferents that are primarily responsible for the facilitatory effects of the conditioning stimuli, although some A delta afferents may contribute. Capsaicin pretreatment does not modify the reflex response to the test stimulus. The most prolonged increase in the excitability of the flexor reflex resulted from intraarticular injections of $5 \mu \mathrm{l}$ mustard oil. Using the subsequent injection of lignocaine intraarticulary, it was found that the prolonged facilitation of the reflex is triggered by the afferent input generated by the conditioning stimulus and does not require an ongoing input for its maintenance. These results indicate that there is a spectrum of central changes in the stimulus response relations of the spinal cord resulting from the activation of $C$-fibers of different origins. The prolonged duration of some of these changes means that the peripheral activation of $\mathrm{C}$-afferents will modify the functional response of the spinal cord to other inputs applied long after the conditioning input, and this may be responsible for some of the sensory and motor alterations found after peripheral tissue injury.

Unmyelinated $\mathrm{C}$-fibers constitute the majority of afferents in the dorsal roots of all mammalian species (Willis and Coggeshall, 1978). In the rat, only cutaneous C-fibers have been studied, and most of these are activated exclusively by intense me-

\footnotetext{
Received July 15, 1985; revised Oct. 22, 1985; accepted Oct. 30, 1985.

This work was supported by the Medical Research Council and the Wellcome Trust. We wish to thank Steve McMahon for his assistance with the single-unit recordings.

Correspondence should be addressed to C. J. Woolf, Cerebral Functions Research Group, Department of Anatomy, University College London, Gower Street, London WC1E 6BT, United Kingdom.

Copyright (c) 1986 Society for Neuroscience $0270-6474 / 86 / 051433-10 \$ 02.00 / 0$
}

chanical, thermal, or chemical stimuli and are typical polymodal nociceptors (Fleischer et al., 1983; Lynn and Carpenter, 1982). Small-diameter afferents from muscle, tendons (Mense and Meyer, 1985), and joints (Schiable and Schmidt, 1983) have been studied in the cat and consist of a mixture of low- and high-threshold units, with the majority of C-fibers falling into the latter category. C-fibers terminate in the superficial dorsal horn (Light and Perl, 1979), where many interneurons are excitcd directly or indirectly by the arrival of a volley in C-afferents (Fitzgerald and Wall, 1980; Woolf and Fitzgerald, 1983). It has now become apparent from experiments in our laboratory that in addition to the rapid excitation over the millisecond range evoked by $\mathrm{C}$-afferents, a very prolonged heterosynaptic facilitation in the spinal cord, lasting for minutes, is also produced (Wall and Woolf, 1984; Woolf, 1983a). The long-duration facilitation is most conveniently seen in the action of a brief conditioning volley in C-primary afferents on the flexor withdrawal reflex circuit in the decerebrate spinal rat (Wall and Woolf, 1984). Not all C-afferent fibers are equally effective in producing such prolonged facilitations. A brief conditioning train of stimuli sufficient to activate C-fibers $(1 \mathrm{~Hz}, 20 \mathrm{sec}$ ) when applied to a cutaneous nerve facilitates the flexor reflex evoked by other afferents for some $5 \mathrm{~min}$, while a similar conditioning volley to a muscle nerve results in about an hour of facilitation. These facilitations are not produced if only myelinated $A$ afferents are activated by the conditioning stimulus (Wall and Woolf, 1984).

In order to define more accurately the origin and nature of peripheral conditioning inputs that can produce prolonged augmentations of the flexor reflex, we have now used two methods of activating C-afferents in addition to electrical stimulation. First, we have used the chemical irritant mustard oil. Mustard oil when applied to human skin produces an intense burning sensation and in the rat it evokes a powerful sustained flexion reflex (Woolf and Swett, 1984) and a neurogenic extravasation that is capsaicin-sensitive (Jancso, 1968). Using single-unit recordings, we have now found that mustard oil activates the majority of cutaneous C-fibers with minimal, if any, effect on A delta afferents. Because of this, we have applied the mustard oil as a general activator of chemosensitive C-afferent terminals to the skin and injected it intramuscularly and intraarticularly. To activate high-threshold muscle and tendon afferents we have also used prolonged maximal tetanic muscle contraction, which in man produces a cramplike pain and in the cat activates a particular group of high-threshold group III and IV muscle afferents (Mense and Stahnke, 1983).

As a means of attempting to establish whether the conditioning stimuli that produce prolonged facilitation do so only by the activation of $\mathrm{C}$-afferent fibers, we have investigated whether the neurotoxin capsaicin abolishes these effects. Local treatment of peripheral nerves with capsaicin produces at $14 \mathrm{~d}$ posttreatment a loss of peptides from the central terminals of the treated 
nerves (Ainsworth et al., 1981) and a substantial decrease in the postsynaptic excitation of interneurons by a C-afferent volley (Fitzgerald and Woolf, 1982; Wall and Fitzgerald, 1981), and it raises the behavioral threshold for foot withdrawal from hot water (Fitzgerald and Woolf, 1982) or to chemical irritants (Jancso et al., 1980) without affecting the response to pinch. No decrease of the central effectiveness or conduction of afferent volleys in myelinated afferents has been observed (Wall and Fitzgerald, 1981), although there is peripheral block in C-polymodal nociceptor activation (Lynn and Pini, 1984). While the bulk of the evidence available points, therefore, to a selectivc effect of local capsaicin, at moderate doses, on C-afferent fibers, until single-unit studies on sufficiently large numbers of $\mathrm{A}$ delta afferents have been performed, an effect on these afferents cannot be positively excluded.

The central, prolonged cxcitability increases in the flexor reflex produced by C-afferent inputs is likely to contribute to some of the sensory disorders that follow peripheral injury (Woolf, 1983a). Therefore, an understanding of the relative effectiveness of C-fibers originating from skin, joint, and muscle in evoking prolonged facilitations of the reflex will lead both to a greater understanding of the functional role of these afferent fibers and of the mechanisms by which they can modify stimulus-response relations in the spinal cord. A brief report of some of these results has been presented to the Physiological Society (Wall and Woolf, 1985).

\section{Materials and Methods}

All the experiments were performed in acutely decerebrated and spinalized adult Sprague-Dawley rats (200-300 gm). Under ether anesthesia, a carotid artery and the trachea were cannulated. Anesthesia was then maintained with small doses of Althesin (Glaxo). The rats were decerebrated by aspiration of all the cranial contents rostral to the mesencephalon and spinalized via a small laminectomy at T8-T10. The anesthetic was then discontinued. In most animals, gallamine $(10 \mathrm{mg})$ was then administered as a paralytic agent and the animals artifically ventilated. Those animals in which the effects of muscle tetani were studied were not given gallamine. The rectal temperature, expired $\mathrm{PCO}_{2}$, heart rate, and ECG were monitored and maintained within physiological limits.

Recordings of flexor alpha-motoneurons were achieved by exposing the nerve to the posterior head of the biceps femoris and the principal head of semitendinosus (PBST) in the popliteal fossa and splitting fine proximal filaments from it. Criteria for establishing that alpha-motoneurons recorded had properties similar to those previously described by an extracellular (Woolf and Swett, 1984) and intracellular study (Cook and Woolf, 1985a) were as follows: absent or low spontaneous activity, mechanoreceptive fields on the ipsilateral hindpaw, rapidly adapting response to sustained mechanical stimulus, and conduction velocity $\geq 50 \mathrm{~m} \mathrm{sec}^{-1}$.

To monitor the excitability of the flexor reflex, the following standard test stimulus was applied (Wall and Woolf, 1984). A calibrated (150 $\mathrm{gm}$ ) pinch was applied for $3 \mathrm{sec}$ to the middle three toes of either the foot ipsilateral or contralateral to the recording site. The spike shape was monitored continuously by an analog delay line. The test stimulus was applied at $5 \mathrm{~min}$ intervals during the course of the experiment, except after a conditioning stimulus, when measurements were made every minute for $5 \mathrm{~min}$.

The total number of spikes elicited by the test stimulus was counted by a pulse integrator. Prior to any conditioning stimulus, a baseline value was obtained by repeating the test stimulus at $5 \mathrm{~min}$ intervals for at least $30 \mathrm{~min}$. The duration of the excitability increase produced by any conditioning stimulus was calculated as the time taken for the number of spikes elicited by the test stimulus to return to within $\bar{x} \pm$ 2 SD of the baseline. To represent the data graphically, it was normalized by expressing each individual test response as a percentage of the mean preconditioning baseline response.

Various conditioning stimuli were used in the different experiments. Electrical stimuli were applied to the sural nerve and the nerve to the gastrocnemius-soleus muscle in gallamine-paralyzed animals, and stimuli to the tibial nerve both in unparalyzed and paralyzed animals. The intensities of stimulation were selected to activate either large myelinat- cd afferents or efferents $(100 \mu \mathrm{A}, 50 \mu \mathrm{sec})$ or all fibers including the $\mathrm{C}$-afferents $(5 \mathrm{~mA}, 500 \mu \mathrm{sec})$. These values have been found by recording dorsal root compound potentials to reliably activate either large myelinated afferents only or C-fibers (Woolf and Wall, 1982). To activate chemosensitive afferents, the chemical irritant mustard oil (20\% in mineral oil) was administered either onto the skin or injected into muscles $(5 \mu \mathrm{l})$ or the knee or ankle joint $(5 \mu \mathrm{l})$. The joints were cannulated by a 31 gauge needle attached to PE10 polyethylene catheters, and the sites of injection verified with dye injections.

In order to test the selectivity of the mustard oil on $\mathrm{C}$ as opposed to A delta afferents, a single-unit study was performed on 24 afferents (13 A delta and $11 \mathrm{C}$ ) innervating the skin of the hindpaw (tibial, sural, and saphenous nerves). The units were classified on the basis of their conduction velocity, obtained by stimulating their cutaneous receptive fields with pin clectrodes.

In several animals the sciatic nerve was pretreated with the $C$-fiber neurotoxin capsaicin prior to the electrophysiological experiments. This procedure was performed under pentobarbitone anesthesia. The sciatic nerve was exposed and locally treated with $1.5 \%$ capsaicin (dissolved in olive oil) for $15 \mathrm{~min}$ (Wall and Fitzgerald, 1981). Olive oil alone has no effect. These animals recovered uneventfully, and the effectiveness of the treatment was tested by measuring the latency of foot withdrawal in the hot water foot immersion test (Fitzgerald and Woolf, 1982). In four animals, peripheral nerves were sectioned approximately $2 \mathrm{hr}$ before the electrophysiological experiments to denervate hairy skin of the hindpaw (sural, saphenous, and superficial perineal nerves) or the glabrous skin (tibial nerve). The peripheral innervation fields of these nerves has been established in a previous study (Swett and Woolf, 1985). All results given are means \pm SEM.

\section{Results}

\section{Test cutaneous stimulus and the hamstring flexor response}

\section{Normal animals}

PBST alpha-motoneurons are characterized in the decerebrate spinal rat, in the absence of any conditioning stimuli, by cither the absence of spontaneous activity $(68 \%, n=25)$ or by very low levels of spontaneous discharge $(1.5 \pm 0.5 \mathrm{~Hz}, n=8)$. These motoneurons generate a brief, high-frequency discharge following suprathreshold mechanical stimulation of the skin of the ipsilatcral hindpaw (firm pressure or pinch), which peaks within 200-400 msec of the stimulus and adapts rapidly so that the response lasts for only $1.3 \pm 0.1 \mathrm{sec}, n=25$ (Cook and Woolf, 1985a; Woolf and Swett, 1984). The response curve to mechanical stimuli of increasing force is very steep once threshold is exceeded, but then plateaus such that progressively greater stimuli at forces greater than twice threshold will not produce greater responses. Because the reflex is organized to generate a limited explosive burst of activity, the response to a standard suprathreshold test mechanical stimulus $(150 \mathrm{gm})$ applied for a period greater than the adaptation time $(3 \mathrm{sec})$ to the same area (across the plantar and dorsal surfaces of the middle three toes) is remarkably stable in terms of the total number of spikes evoked by the test stimulus when repeated over $3 \mathrm{hr}$, the mean of the SD from the baseline in five animals being $4.7 \pm 0.6 \%$. In addition to the ipsilateral response, a smaller response could be evoked in $72 \%$ of the motoneurons by applying the test stimulus to the contralateral foot.

\section{Effect of capsaicin on the unconditioned test flexion reflex}

The response in PBST alpha-motoneurons following the standard pressure stimulus to the toes was examined in nine rats 12-14 d after their sciatic nerves had been treated with capsaicin as described under Materials and Methods. No significant difference was observed in the mean threshold, intensity, or duration of the flexor response to mechanical stimuli in any of these rats. The effectiveness of the capsaicin treatment was tested by measuring the latency to withdrawal of the foot from water at $50^{\circ} \mathrm{C}$ and by recording the C-fiber-evoked discharge of motoneurons. In each animal the latency to foot withdrawal on the 

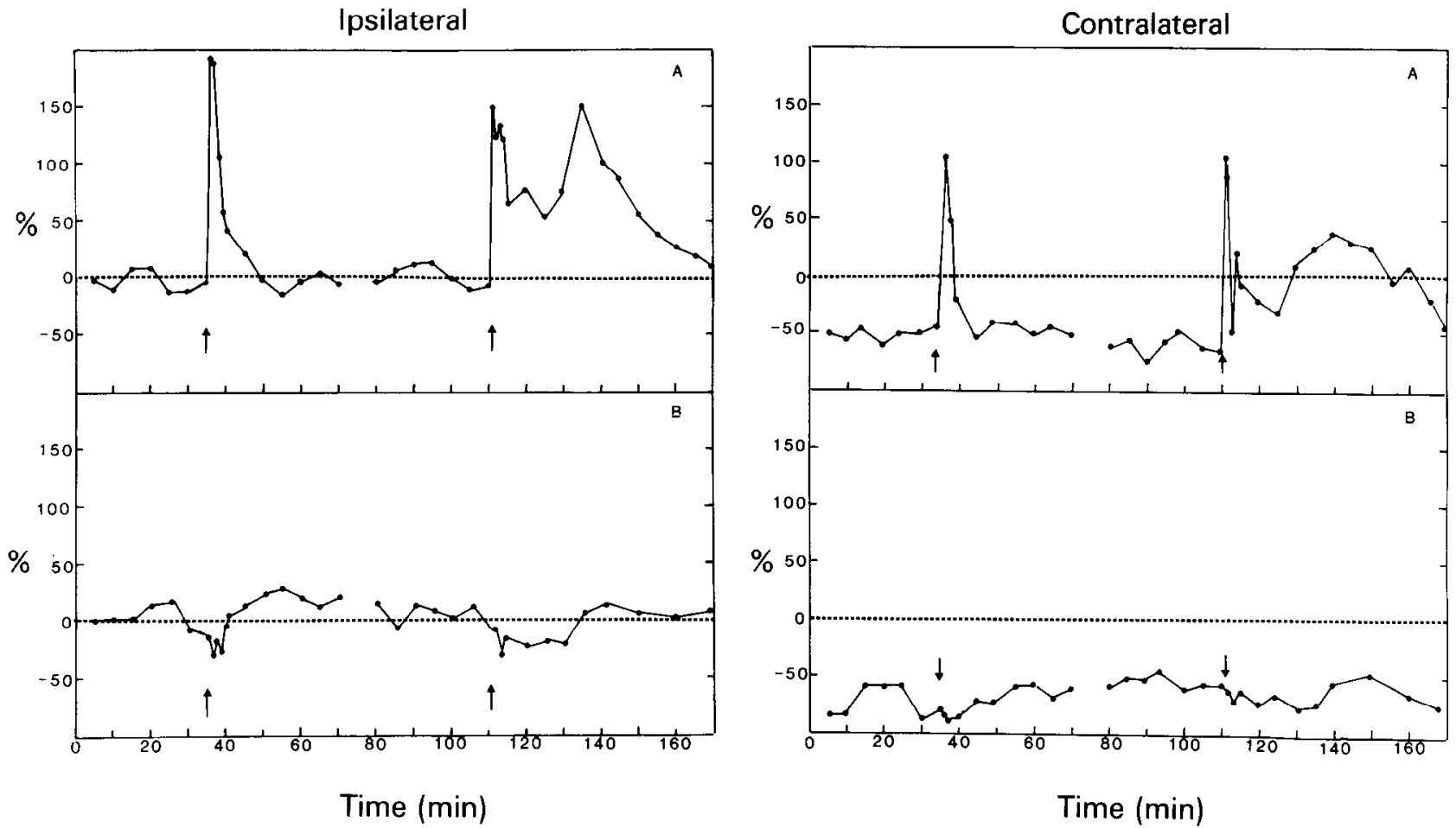

Figure 1. Graph illustrating the change in the excitability of the flexor reflex following a sural (left arrow) and a gastrocnemius-soleus nerve (right arrow) conditioning stimulus ( $20 \mathrm{sec}, 1 \mathrm{~Hz}, \mathrm{C}$-fiber strength) in a control rat $(A)$ and in a rat whose sciatic nerve was pretreated $14 \mathrm{~d}$ earlier with capsaicin $(B)$. Left panel, Change in the excitability of the reflex expressed as the percentage deviation from the preconditioning baseline response to the ipsilateral test stimulus. Right panel, Change in response to the contralateral test stimulus expressed as a percentage of the mean preconditioning ipsilateral test response. Capsaicin abolishes both the ipsi- and contralateral test increases in the reflex that occur following the conditioning stimuli in the control animals.

side ipsilateral to the capsaicin treatment was at least twice that obtained from the contralateral foot, while in none of the animals could the characteristic long-latency C-evoked discharge be evoked in the motoneurons by stimulation of the sural nerve at $\mathrm{C}$-fiber strength, although both the short- and intermediatelatency myelinated afferent-mediated reflexes were present. These results show that the high-threshold mechanoreceptor A delta input activated by the test pinch stimulus is adequate to evoke an apparently normal flexion withdrawal reflex in the absence of a measurable $\mathrm{C}$-input. The response of the animals to the noxious thermal stimulus was not abolished, just delayed. This indicates either that some A delta afferents respond to thermal stimuli (Lynn and Carpenter, 1982) or that the capsaicin does not block all C-fiber input into the spinal cord.

\section{Conditioning effect of $C$-afferent volleys of cutaneous origin}

\section{Brief afferent volleys}

The sural nerve was stimulated at C-fiber strength for $20 \mathrm{sec}$ at $1 \mathrm{~Hz}$. The test flexion reflex was maximally exaggerated by 1 min after the end of the conditioning train and declined to the baseline within 3-5 min (Fig. $1 A$ ). This effect was observed both when the test stimulus was applied ipsi- and contralateral to the motoneurons. This confirms our previous observations (Wall and Woolf, 1984). In four animals in which the sciatic nerve had been treated with capsaicin, sural nerve stimulation completely failed to produce an increase in the test flexion reflex and actually produced a transient inhibition in three cases (Fig. $1 B)$.

\section{Prolonged volleys}

In four animals, the sural nerve was stimulated at $2 \mathrm{~Hz}$ for 10 min. In three of the animals the ipsilaterally evoked flexion reflex was elevated for more than $3 \mathrm{hr}$ by this conditioning stimulus (Fig. $2 A$ ), and in one it lasted for $70 \mathrm{~min}$ (Fig. $2 B$ ). The reflex evoked by contralateral stimulation was also exaggerated by this prolonged conditioning, but for a shorter time (Fig. 2).

\section{Mustard oil applied to the skin}

Mustard oil applied to the cutaneous receptive fields of 24 slowly conducting single afferents (11 Cs and $13 \mathrm{~A}$ deltas) activated 8 of the units. One of these, with a conduction velocity of $1.9 \mathrm{~m}$ $\mathrm{sec}^{-1}$, was a borderline A delta/C afferent; the other 7 had conduction velocities lower than $1.5 \mathrm{~m} \mathrm{sec}^{-1}$. A total of 7 out of $11 \mathrm{C}$-afferents responded to the mustard oil, while none of the A delta afferents, other than that with the conduction velocity of $1.9 \mathrm{~m} \mathrm{sec}^{-1}$, responded. In none of the strands with rapidly conducting A beta afferents did the mustard oil evoke a response in these low-threshold afferents.

When $100 \mu \mathrm{l}$ of mustard oil was applied to the hairy skin on the lateral and dorsal surface of the hindpaw ipsilateral to the recording site (innervated by the sural and superficial peroneal nerves), a burst of activity developed in the PBST motoneurons within 15-40 sec and lasted for $2.9 \pm 0.6 \mathrm{~min}(n=5$, Fig. 3$)$. This direct activation of the motoneurons did not occur if the mustard oil was applied to the contralateral foot $(n=4)$, nor did it occur if the sciatic nerve had been pretreated with capsaicin $(n=4)$. This indicates that, whatever afferents mustard oil activates, they are capsaicin sensitive. Long after the induced firing of the flexor motoneurons died down there was a profound facilitation of the flexor reflex evoked both by ipsi- and contralateral test stimuli, lasting $101 \pm 14 \mathrm{~min}(n=5$, Fig. $4 \mathrm{~A}$ ). Prolonged facilitation of the reflex did not occur with application of the mustard oil to the hindpaw contralateral to the recording site $(n=3)$, nor did it occur if mustard oil was applied ipsilat- 

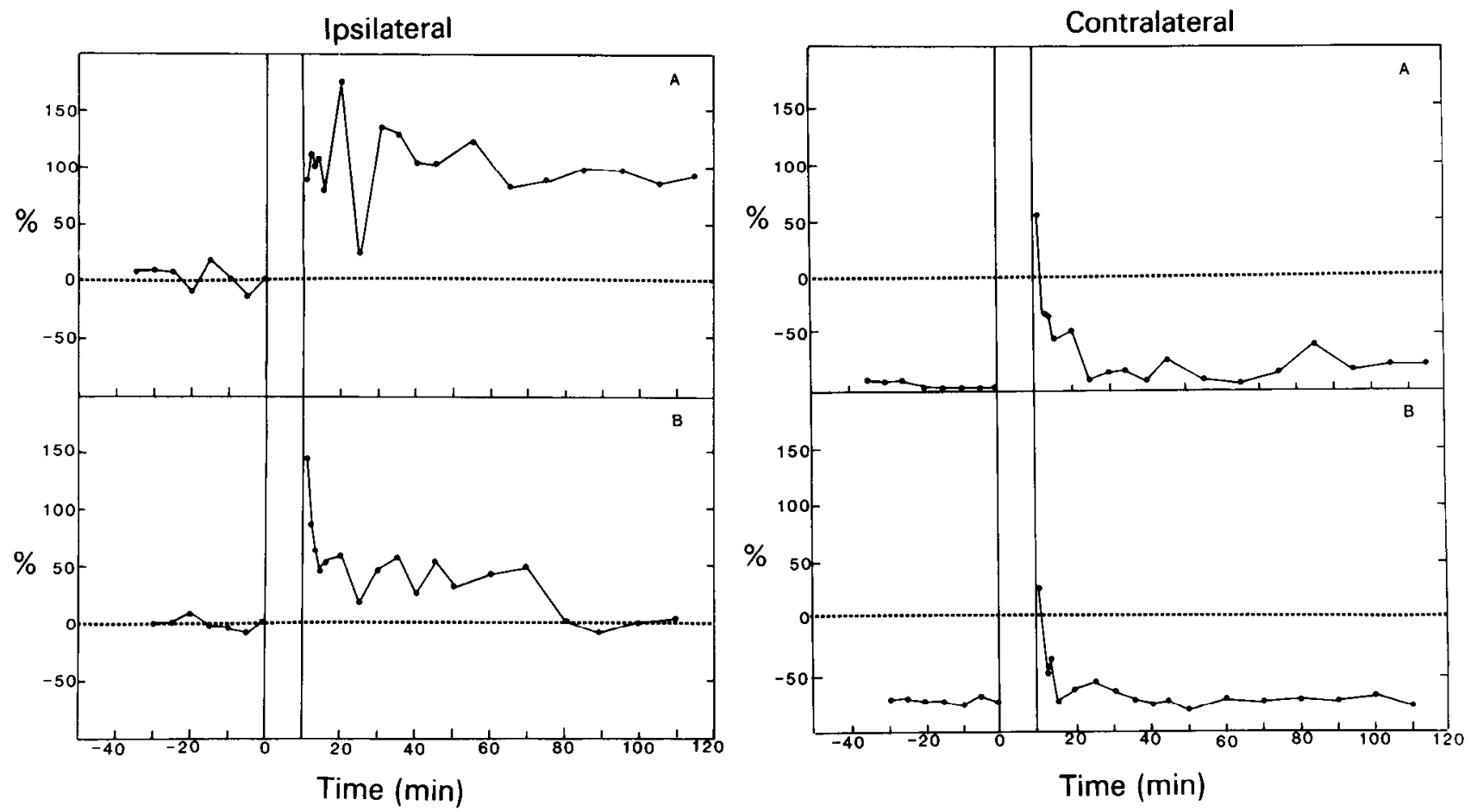

Figure 2. Changes in the excitability of the flexor reflex to ipsilateral (left) and contralateral (right) standard test mechanical stimuli produced by a $2 \mathrm{~Hz}$ conditioning stimulus to the sural nerve at $\mathrm{C}$-fiber strength for $10 \mathrm{~min}$ (solid lines) in two individual rats $A$ and $B$.

erally after the sciatic nerve had been pretreated with capsaicin $(n=4)$. The application of $5 \mu \mathrm{l}$ of mustard oil to the skin was insufficient to induce the effect.

In order to test whether the C-afferents innervating hairy and glabrous skin both have the capacity to produce prolonged facilitations, the following experiments were performed. The tibial nerve, which innervates $90 \%$ of the glabrous skin and no hairy skin, was sectioned in two rats $2 \mathrm{hr}$ before recording was started, effectively denervating the glabrous skin; in two others, the nerves innervating the hairy skin were sectioned (sural, saphenous, and superficial nerves). In the former case (hairy skin innervated), the mustard oil applied to the dorsum of the foot produced a prolonged facilitation similar to that in the intact animal (Fig. $4 B$ ); in the latter case (only glabrous skin innervated), facilitation occurred if the mustard oil was applied to the plantar surface of the foot, but its onset was considerably delayed (Fig. $4 C$ ).
These differences may reflect differences in penetration of the drug or in the properties of the C-fibers innervating the two different types of skin. Nevertheless, both populations of C-fibers can produce prolonged alterations in the responsiveness of the spinal cord.

\section{Conditioning effect of afferent volleys of joint origin}

Intraarticular injections of $5 \mu \mathrm{l}$ of saline into either the knee or ankle joint had no effect on the test hamstring flexor reflex. When $5 \mu \mathrm{l}$ mustard oil was injected, a large sustained increase in the reflex developed, even though there was no induced firing of the motoneurons. The increased excitability persisted up to the termination of the experiment, $180 \mathrm{~min}$ after the injection $(n=4$, Fig. $5 A$ ). Both the responses to ipsi- and contralateral test stimuli were exaggerated. At the end of the experiment, dye was injected through the needle into the joint and was found to
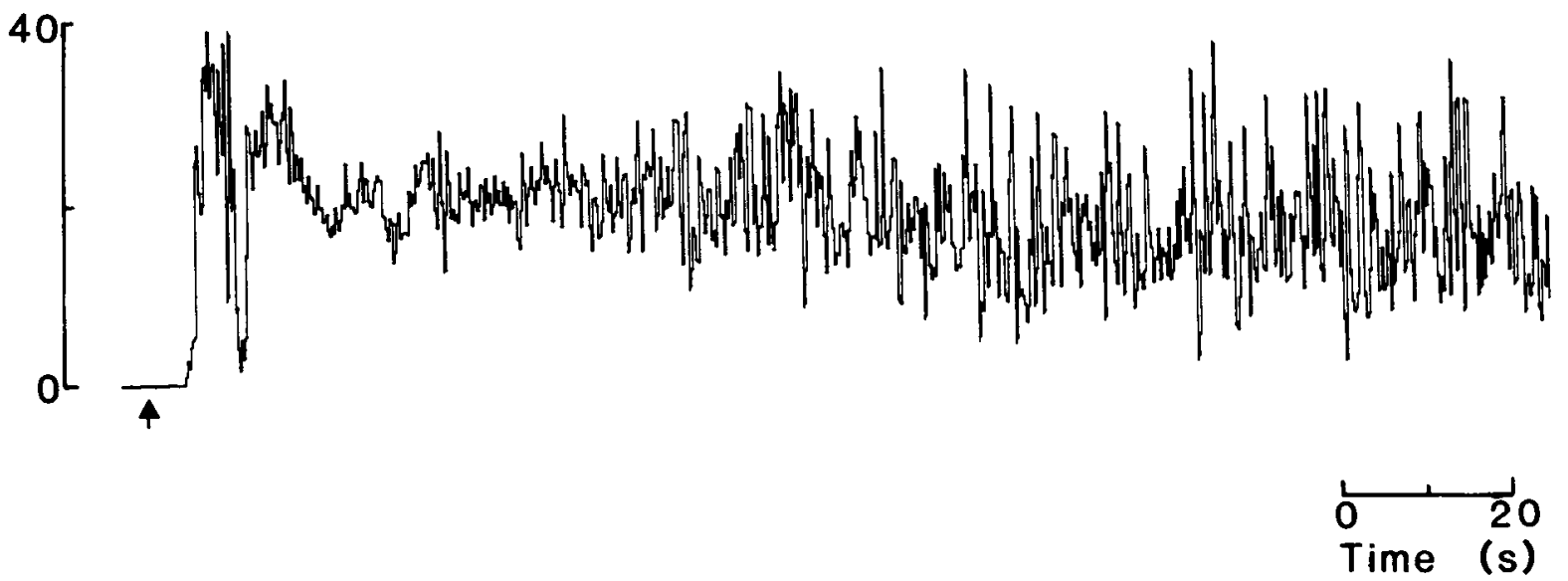

Figure 3. Ratemeter recording of the activity evoked in a PBST alpha-motoneuron following the application of mustard oil to the hairy skin of the hindpaw ipsilateral to the recording side. Vertical scale represents number of spikes per $200 \mathrm{msec}$ bin. 

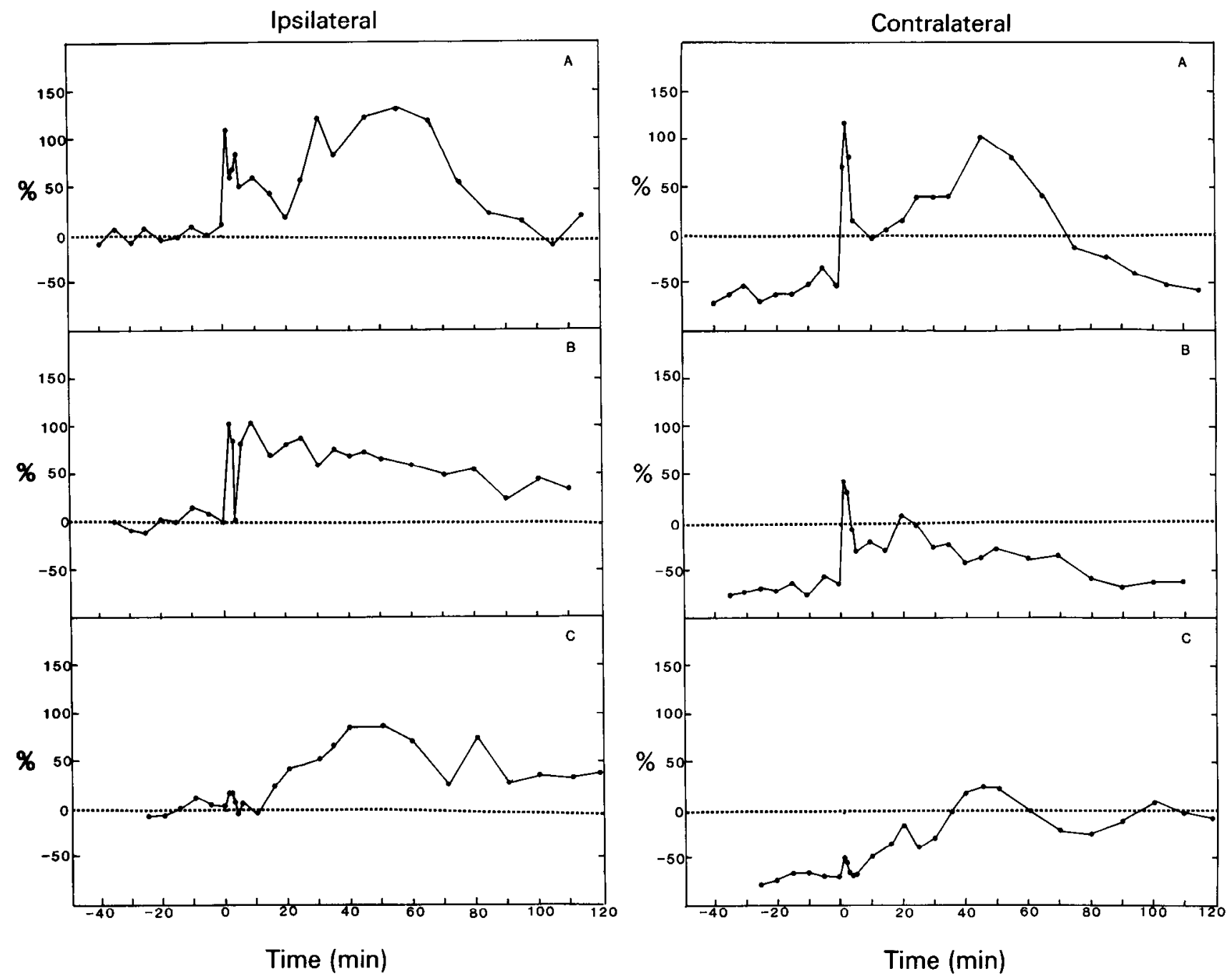

Figure 4. Changes in the magnitude of the flexor reflex to ipsilateral (left) and contralateral (right) standard mechanical test stimuli following $(A)$ application of mustard oil to the hairy skin of the ipsilateral hindpaw, $(B)$ the application of mustard oil to the hairy skin of the hindpaw in a rat with a sectioned tibial nerve, and $(C)$ the application of mustard oil to the flabrous skin of the hindpaw in a rat with sectioned saphenous, sural, and superficial peroneal nerves. The mustard oil was applied at time 0 . The area of skin treated with the mustard oil $\left(\sim 5 \mathrm{~mm}^{2}\right)$ was the same in each animal.

have flooded the synovial cavity. In two other animals, it was found at the end of the experiment that the needle had failed to penetrate the joint capsule and that the mustard oil and the subsequent dye had been applied only to connective tissue near the joint. In these two animals, the excitability increase lasted only 25 and $90 \mathrm{~min}$.

We wished to test if the prolonged facilitation was not only triggered but was perhaps sustained by a continuing action of the mustard oil in the joint. For this reason, we injected $5 \mu \mathrm{l}$ $2 \%$ lignocaine into the joint 30 min after the mustard oil had been injected ( $n=3$, Fig. $5 B$ ). This injection failed to influence the time course of the facilitation. In order to demonstrate that such an injection was sufficient to produce anesthesia of the joint and was able to prevent the excitatory action of mustard oil, we injected $5 \mu \mathrm{l}$ of $2 \%$ lignocaine $5 \mathrm{~min}$ before the mustard oil was injected ( $n=2$, Fig. $5 C)$. In these animals, neither the local anesthetic nor the subsequent intrasynovial mustard oil produced any effect on the flexor reflex. In order to show that the mustard oil was having its facilitatory effect by way of capsaicin-sensitive afferents, it was injected into the ankle joint of two rats whose sciatic nerve and saphenous nerves had been treated $14 \mathrm{~d}$ earlier with capsaicin. Capsaicin pretreatment com- pletely blocked the excitability increase following intraarticular mustard oil.

\section{Conditioning effects of afferent volleys of muscle origin}

\section{Brief afferent volleys}

We confirmed (Wall and Woolf, 1984) that a brief train of electrical stimuli $(1 \mathrm{~Hz}, 20 \mathrm{sec})$ applied to the nerve to gastrocnemius-soleus at a strength sufficient to excite C-fibers produced a prolonged facilitation of the flexor reflex $(n=5$, Fig. 1). The facilitation was marked within 1 min of the end of the conditioning stimulus and then declined, followed by a second delayed increase that began at $5-10 \mathrm{~min}$, peaked at $20-40 \mathrm{~min}$, and lasted up to $90 \mathrm{~min}$. In four animals whose sciatic nerve had been pretreated with capsaicin, there was no sign of this prolonged facilitation (Fig. 1).

\section{Tetanic contraction}

In four animals not paralyzed with gallamine, the flexion reflex was evoked and recorded in the usual way. A low-intensity $(100$ $\mu \mathrm{A}, 50 \mu \mathrm{sec})$ conditioning stimulus sufficient to excite the axons of alpha motoneurons was then applied to the tibial nerve. This 

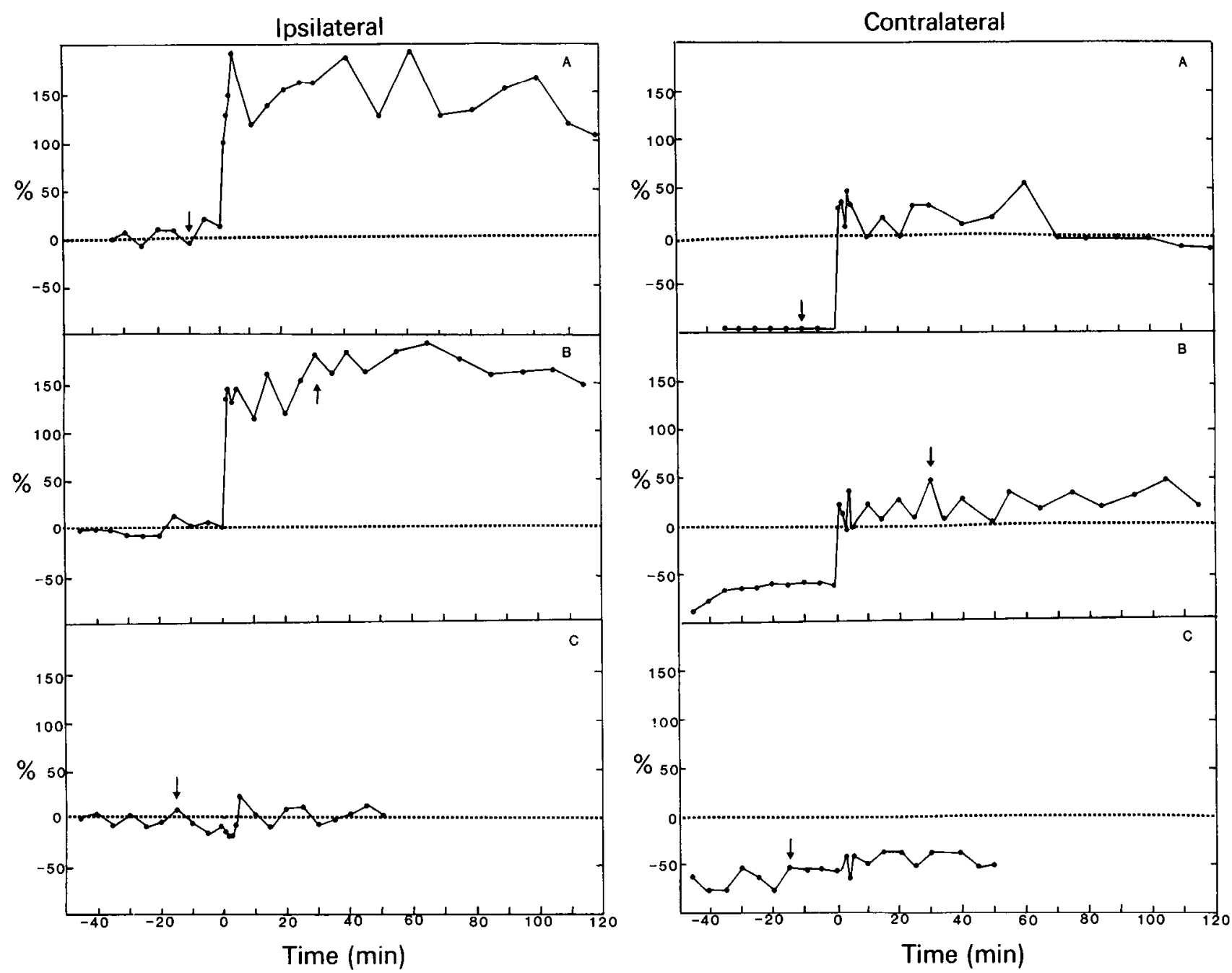

Figure 5. Changes in the excitability of the flexor reflex to ipsi- and contralateral test stimuli produced by intraarticular injections. $A$, The arrow indicates that $5 \mu \mathrm{l}(0.9 \%) \mathrm{NaCl}$ did not alter the reflex, but $5 \mu \mathrm{l}$ mustard oil (time 0 ) produced increased responses to both the ipsi- and contralateral test stimuli. $B$, Mustard oil $(5 \mu \mathrm{l})$ was injected at time 0 , and then $5 \mu \mathrm{l}$ lignocaine ( $2 \%$ ) was also injected (arrow). This failed to modify the mustard oil induced changes. $C$, Lignocaine, $5 \mu \mathrm{l}(2 \%)$, was injected (arrow) and then, at time $0,5 \mu \mathrm{l}$ mustard oil was administered, which did not increase the excitability of the reflex.

nerve supplies the gastrocnemius, soleus, plantaris, flexor hallucis longus, flexor digitorum longus, and tibialis posterior muscles. It should be stressed that it does not supply the posterior biceps femoris and semitendinosus, in which the test response was being observed. The conditioning stimulus applied to the tibial nerve at $50 \mathrm{~Hz}$ was sufficient to produce a tetanic contraction in the muscles it supplies. The tetanic contraction was followed by an increase of the test ipsilateral flexor reflex within $1 \mathrm{~min}$, but it did not affect the reflex evoked by contralateral test stimulation (Fig. 6). The duration of the excitability increase depended on the duration of the muscle tetanus (Fig. 7), so that a $60 \mathrm{sec}$ tetanus produced the maximal duration of excitability increase $-40 \mathrm{~min}$. Tetani lasting less than $10 \mathrm{sec}$ did not produce an increase, while those lasting longer than $60 \mathrm{sec}$ did not prolong the increase produced by $60 \mathrm{sec}$ tetani. The duration of the facilitation produced by the tetanus was less than that produced by electrical stimulation of the gastrocnemius-soleus nerve (Fig. 1). This suggests that the tetanus was not an adequate stimulus for all the small-diameter afferents.

It might be proposed that the effect on the reflex excitability produced by tibial nerve stimulation was produced by the afferent volley generated in large-diameter afferent fibers rather than by the muscle contraction. That this was not the case was shown by repeating the conditioning stimulus after gallamine paralysis. First, the tibial nerve was stimulated in unparalyzed animals to generate a muscle tetanus; the flexor reflex exaggeration followed until it had returned to the baseline. Then, the animal was paralyzed with $10 \mathrm{mg}$ of systemic gallamine and artificially respired. This procedure did not affect the amplitude of the test reflex evoked by the standard pinch. With the animal paralyzed, the tibial nerve was stimulated with exactly the same parameters as used earlier to evoke contraction and prolonged facilitation. This stimulus would evoke an identical direct afferent volley in large myelinated afferents; however, since the muscle did not contract, it would not evoke the indirect afferent volley produced by tetanic contraction. In each animal $(n=3)$, the large myelinated afferent conditioning stimulus with paralysis evoked a brief, but substantial inhibition lasting about 10 min, rather than the prolonged facilitation (Fig. $6 B$ ). This inhibition resembled that produced by $\mathrm{C}$-fiber strength conditioning stimuli applied to capsaicin-pretreated nerves (Fig. 1), where only myelinated afferents are functionally intact. Stimulation of the sural nerve at an intensity that only activates $\mathrm{A}$ beta afferents in control animals $(n=3)$ also produced an inhibition of the reflex (Fig. 6C). Therefore, the central consequences of $\mathrm{A}$ beta afferent conditioning stimuli are of opposite 

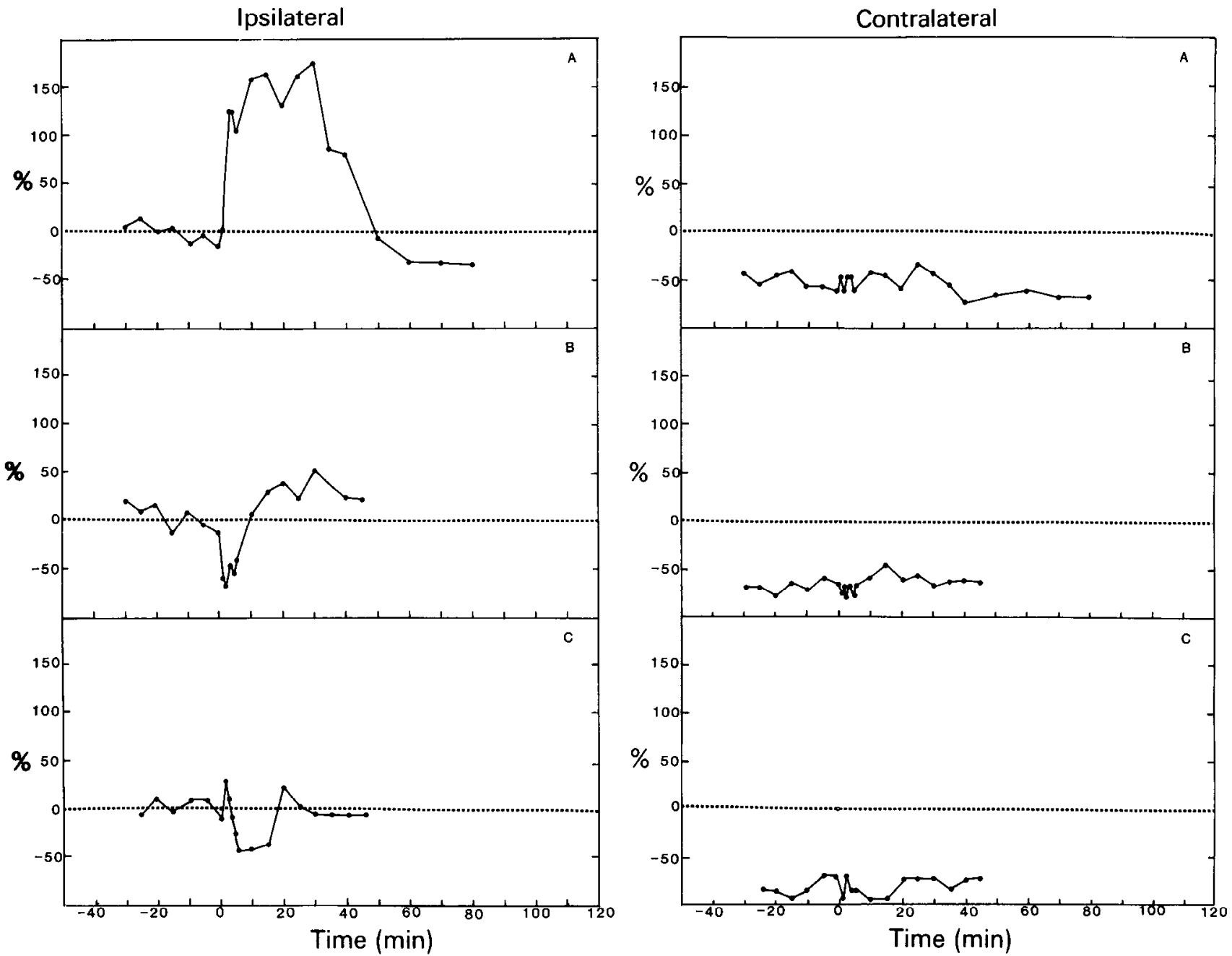

Figure 6. Changes in the excitability of the flexor reflex to ipsi- and contralateral standard test stimuli following $(A) 2$ min fused tetanic contraction of the muscles innervated by the tibial nerve produced by stimulation of the tibial nerve at $50 \mathrm{~Hz}$ at A-fiber strength, $(B)$ stimulation of the tibial nerve at these parameters in a gallamine paralyzed rat, and $(C)$ stimulation of the sural nerve at $50 \mathrm{~Hz}$ for 2 min at A-fiber strength in an unparalyzed rat.

sign to those produced by $\mathrm{C}$-afferent inputs.

In three unparalyzed animals whose sciatic nerve had been treated with capsaicin 12-14 d before the observation, a tetanic conditioning stimulus produced the expected muscular contraction, but this was not followed by a prolonged facilitation (Fig. 7). In those animals in which the tetanus lasted for $60 \mathrm{sec}$, a short $(<4 \mathrm{~min})$ period of facilitation was followed by up to a $5 \mathrm{~min}$ inhibition. A tetanus of $3 \mathrm{~min}$ produced a longer facilitation ( $8 \mathrm{~min}$ ), although still considerably less than in the untreated animals. This may mean either that not all the afferents were adequately blocked by the capsaicin or that there is a capsaicin-insensitive group of afferents activated by the tetanus that can produce a short excitation of the hamstring reflex.

\section{Mustard oil in muscle}

When $5 \mu \mathrm{l}$ of mustard oil was injected into the body of the gastrocnemius muscle in two animals, there were 20 and $30 \mathrm{~min}$ periods of facilitation of the test reflex. These injections did not produce any firing in the motoneurons.

\section{Discussion}

The major finding of the present study is that noxious stimuli of an intensity sufficient to activate capsaicin-sensitive primary afferent neurons in skin, muscle, or joints generate a heterosyn- aptic, prolonged facilitation of the flexor reflex. That the excitability increase is likely to be due primarily to unmyelinated afferents has been shown by: graded electrical conditioning stimuli; the sensitivity of the phenomenon to a chemical irritant, mustard oil, that appears to maximally activate $\mathrm{C}$-afferents; and the fact that pretreatment of proximal nerves with the neurotoxin capsaicin, which has been shown to block $\mathrm{C}$ and not $\mathrm{A}$ delta function, abolishes the effect. A role for some A delta afferents in the phenomenon cannot, however, be positively excluded until techniques are available for either selectively activating or blocking these afferents. The excitability increase is heterosynaptic because a conditioning stimulus in one group of primary afferents increases the response to other groups of afferents. A conditioning stimulus to muscle $\mathrm{C}$-afferents, for example, increases the response to the high-mechanothreshold tibial and superficial peroneal test inputs. The excitability increase cannot be the result of changes at the peripheral ends of the test primary afferent fibers because the conditioning stimuli in most cases were distant from the test inputs, and in all cases the conditioning stimuli increased the response to contra- as well as ipsilateral test stimuli. Contralateral conditioning stimuli, in contrast, failed to alter the flexor motoneuronal response to either ipsi- or contralateral test stimuli. The response to C-fiber conditioning stimuli is not, therefore, a general one but is 


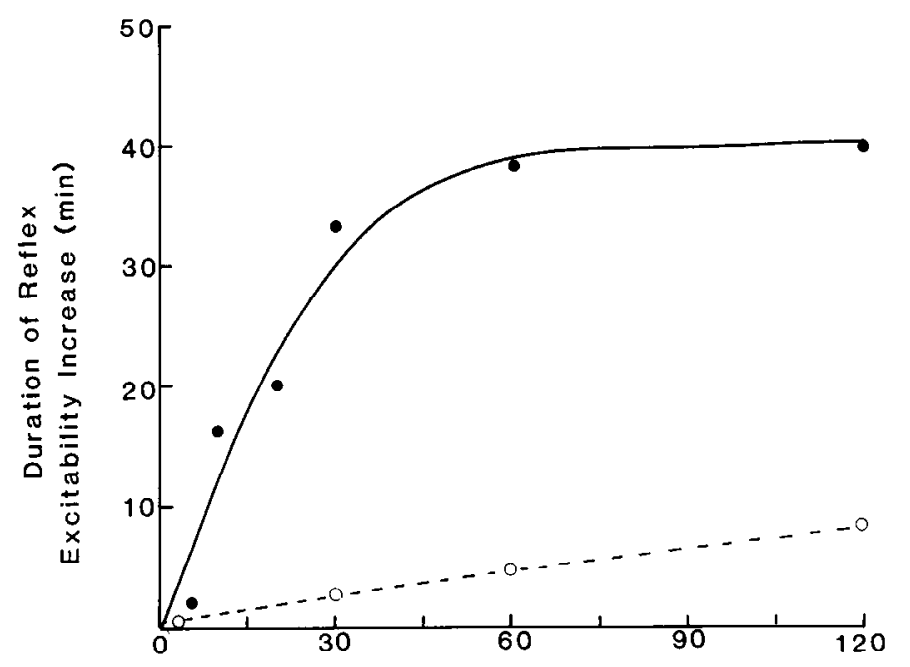

Duration of Tetanus (s)

Figure 7. Graph illustrating the relationship between the duration of tibial muscle tetanus in unparalyzed rats and the period of increased excitability of the flexor reflex. Solid line, Results obtained in four control rats; interrupted line, obtained from rats whose sciatic nerve had been pretreated with capsaicin. Each point represents the mean of two readings from two animals.

spatially organized. The conditioning stimuli do not have to activate the flexor reflex directly in order to alter its stimulusresponse relationships. Intraarticular mustard oil produces a powerful prolonged facilitation of the hamstring moloneuronal response to a standard pinch of the toes, without itself producing any firing in the motoneuron. If such firing does occur, as with conditioning stimuli such as the application of mustard oil to the skin, the direct activation of the motoneurons lasts for only a fraction of the duration of the prolonged facilitation. These results indicate that the conditioning stimuli produce a subthreshold change, modifying the excitability of a cell membrane, somewhere in the chain of neurons that link the test cutaneous afferent terminals and flexor motoneuron.

The C-fiber-induced excitability increase does not appear to operate at the level of the motoneurons. At the same time that polysynaptic cutaneous reflexes are greatly facilitated by $\mathrm{C}$-afferent conditioning stimuli, the homonymous monosynaptic reflex elicited by Ia afferents in the flexor motoneuron is unaltered (Cook and Woolf, 1985b). In this respect, and also in terms of its duration, the C-fiber excitability increase is quite unlike homosynaptic posttetanic potentiation of motoneurons (Mendell, 1984). At present, we have no information as to where contralateral cutaneous inputs converge to activate the flexor motoneurons, but the finding that ipsilateral conditioning stimuli can increase the contralateral test input may assist the study of which set of neurons is first subject to excitability changes.

Conditioning stimuli to skin, muscle, and joints all produced a postconditioning excitability increase. Although brief electrical conditioning stimuli $(1 \mathrm{~Hz}, 20 \mathrm{sec})$ to a cutaneous and a muscle nerve showed that muscle afferents were more efficacious than skin afferents in producing prolonged excitability changes, the present findings indicate this may not be an absolute difference, but may depend on the pattern and duration of the conditioning input. Certainly, mustard oil applied to a hindpaw, innervated only by cutaneous nerves [with the muscle nerves cut (Fig. $4 B$ )], still produced a prolonged excitability increase. A prolonged sural tetanus $(10 \mathrm{~min}, 2 \mathrm{~Hz}$ ) also evoked longduration excitability increases that shorter trains of conditioning stimuli did not. Electrical conditioning stimuli are, however, artificial both in terms of the synchronization of the afferent inputs and in the way they simultaneously activate functionally different afferent fibers. The simultaneous activation of A- and C-fibers might result either in a summation of their central excitatory effects or in inhibitory influences of one afferent input on another. Both A- and C-afferent volleys have the capacity to produce inhibition in the dorsal horn (Woolf, 1983b; Woolf and Wall, 1982). Cutaneous A-afferent fibers can alter the terminal excitability of C-afferents (Fitzgerald and Woolf, 1981). Therefore, one possibility for why the brief electrical stimulation of sural nerve produces a shorter facilitation than the gastrocnemius-soleus nerve is that the segmental afferent inhibition produced by the sural A-afferents is greater than that produced by the muscle afferents. We have now shown that stimulation of sural A beta afferents (Fig. 6C) does produce inhibition of the reflex. Since mustard oil activates only cutaneous C-afferents, they are now able to produce, unhindered by any inhibitory influences, their full facilitatory effects.

It is unlikely, though, that a difference in inhibitory influences is the only factor that determines the duration of the facilitation produced by C-afferents of different origins. Table 1 shows the spectrum of abilities of C-fibers of different origins to set off prolonged facilitation, ranging from maximal effects from intraarticular injections of mustard oil to the short facilitations produced by sural conditioning stimuli. Part of the differences may reflect densities of innervation. The synovium may have more afferent terminals per unit area than the skin or muscle. Part may reflect the most appropriate adequate stimuli for different tissues. The synovium may have more chemosensitive afferents than the skin. Unfortunately, there are no data concerning this in the rat. In the cat, a proportion of joint afferents have high mechanical thresholds (Schiable and Schmidt, 1985), and some of these are chemosensitive (IIong et al., 1978). It is unlikely, though, that the differences in the ability of different nerves to produce facilitation reflect simple differences in the numbers of afferents. In the cat, for example, the number of $\mathrm{C}$-fibers in the sural nerve is considerably higher than that in the gastrocnemius-soleus nerve (McLaughlin and Jänig, 1983). The duration of the discharge in the different afferent fibers may be important, although the fact that local anesthetic injections 30 min after intraarticular administration of mustard oil failed to abolish the excitability increase indicates that an ongoing affcrent barrage is not required to sustain the excitability changes.

One of the most probable reasons for the differences in the central effects of different $\mathrm{C}$-afferent fibers is that different C-fibers contain different neuropeptides or neuromodulators. The $\mathrm{C}$-afferent cell bodies in the lumbar dorsal root ganglia, for example, contain a variety of different peptides-substance $\mathrm{P}$, somatostatin, cholecystokinin, calcitonin gene-related peptide-some of which coexist (Gibson et al., 1984; Hökfelt et al., 1980). Many (up to $50 \%$ ) of the cell bodies also contain the enzyme fluoride-resistant acid phosphatase (FRAP) (Nagy and Hunt, 1982). We have previously examined the sural and gastrocnemius nerves for some differences in their neurochemical content (McMahon et al., 1984). The sural nerve when ligated accumulates large amounts of substance $P$ and FRAP, while the gastrocnemius-soleus nerve has very low levels of these markers. It would be of great interest to establish what peptides the $\mathrm{C}$-afferents innervating joints and muscles contain, because peptides have been shown to produce prolonged subthreshold excitations (Urban and Randic, 1984; Woolf and Wiesenfeld-Hallin, 1985) similar to that we have found following C-conditioning stimuli.

Differences in the central termination of the C-afferents may also be important. The central termination of cutaneous C-fibers has been studied by a number of techniques, including HRP transport (Light and Perl, 1979) and the disappearance of mark- 


\begin{tabular}{|c|c|c|c|}
\hline Source & Procedure & $\begin{array}{l}\text { Duration } \\
(\mathrm{min})\end{array}$ & $n$ \\
\hline \multirow[t]{7}{*}{ Skin } & Sural nerve stimulation A-fiber strength & 0 & 5 \\
\hline & Sural nerve stimulation C-fiber strength & & \\
\hline & $20 \mathrm{sec}, 1 \mathrm{~Hz}$ & $3-5$ & 12 \\
\hline & $600 \mathrm{sec}, 2 \mathrm{~Hz}$ & $90-180$ & 4 \\
\hline & Mustard oil & & \\
\hline & $100 \mu 1$ & $90-110$ & 5 \\
\hline & $5 \mu \mathrm{l}$ & 0 & 2 \\
\hline Joint & Mustard oil, $5 \mu l$ & $>180$ & 4 \\
\hline Periarticular tissue & Mustard oil, $5 \mu$ l & $25-90$ & 2 \\
\hline \multirow[t]{4}{*}{ Muscle } & $\begin{array}{l}\text { Gastrocnemius-soleus nerve stimulation } \\
\text { A-fiber strength }\end{array}$ & 0 & 4 \\
\hline & $\begin{array}{l}\text { Gastrocnemius-soleus nerve stimulation } \\
\text { C-fiber strength, } 20 \mathrm{sec}, 1 \mathrm{~Hz}\end{array}$ & $50-90$ & 5 \\
\hline & Mustard oil, $5 \mu 1$ & $20-30$ & 2 \\
\hline & Tetanic contraction $(>60 \mathrm{sec})$ & 40 & 4 \\
\hline
\end{tabular}

er substances following peripheral nerve section (Devor and Claman, 1980). These cutaneous C-afferents terminate in an extraordinarily precise map within laminae 1 and 2 (Swett and Woolf, 1985). Unfortunately, these two methods of determining the central termination of C-fibers are not applicable to muscle C-fibers, since they do not contain the two common markers SP and FRAP and since repeated experiments with HRP in various forms with various stains have failed to show any transganglionic transport of HRP by C-fibers (Craig and Mense, 1983; Swett, 1983). Using the physiological technique of antidromic microelectrode stimulation of single $\mathrm{C}$-fibers to map the location of terminal arborizations, we have found that the terminals of muscle afferents appear to be located in lamina 1 and inner lamina 2 and in lamina 3 (McMahon and Wall, 1985).

The observations on the central effects of input volleys from skin and deep tissue reported here are strikingly reminiscent of some common clinical phenomena. A twisted ankle, for example, which involves relatively minor destruction of tissue, produces an immediate localized stab of pain that dies down in seconds but is followed by a prolonged period of spreading, poorly localized deep pain and tenderness associated with a change in refiexes and gait. The two-phase experience of pain and tenderness has been imitated by the injection into deep tissue of $6 \%$ salinc by Lewis and Kellgren (1939) and by Hockaday and Whitty (1967). Localized skin damage, in contrast, produces an acute burst of pain that steadily dies down over minutes but is associated with a spatially restricted triple response of flair, wheal, and surrounding tenderness. Small skin lesions do not tend to produce as widespread and as prolonged a disturbance of sensation or of reflex patterns as deep injury.

We have previously suggested (Woolf, 1983a) that the tenderness associated with skin injury may be partly the consequence of central changes produced by the injury-induced afferent barrage. Because brief afferent inputs from deep tissue have even more pronounced effects than cutaneous inputs, this may explain the more widespread sensory disturbances that accompany deep injury. The varied pattern of postinjury pain hypersensitivities resulting from injury to different tissues may be the consequences, therefore, of the activation of different afferents with different central actions.

The presence of widespread tenderness (allodynia) with disordered movement is frequently the most disturbing symptom in patients in chronic pain. Therefore, the phenomena we report here deserve further attention as a possible model of a particularly distressing human state.

\section{References}

Ainsworth, A., P. Hall, P. D. Wall, G. Allt, I. M. Mackenzie, S. Gibson, and J. Polak (1981) Effects of capsaicin applied locally to adult peripheral nerve. II. Anatomy and enzyme and peptide chemistry of peripheral nerve and spinal cord. Pain 11:379-388.

Craig, A. D., and S. Mense (1983) The distribution of afferent fibres from the gastrocnemius-soleus muscle in the dorsal horn of the cat as revealed by the transport of horseradish peroxidase. Neurosci. Lett. 41: 233-238.

Cook, A. J., and C. J. Woolf (1985a) Cutaneous receptive field and morphological properties of hamstring flexor alpha-motoneurones in the rat. J. Physiol. (Lond.) 364: 249-263.

Cook, A. J., and C. J. Woolf (1985b) C-afferent fibre induced excitability increase of the flexor reflex is not due to change in motoneurone excitability. Neurosci. Lett. Suppl. 21: S36.

Devor, M., and D. Claman (1980) Mapping and plasticity of acid phosphatase afferents in rat dorsal horn. Brain Res. 190: 17-28.

Fitzgerald, M., and P. D. Wall (1980) The laminar organization of dorsal horn cells responding to peripheral $\mathrm{C}$ fibre stimulation. Exp. Brain Res. 41: 36-44.

Fitzgerald, M., and C. J. Woolf (1981) Effects of cutaneous nerve and intraspinal conditioning on C-fibre afferent terminal excitability in decerebrate spinal rats. J. Physiol. (Lond.) 318: 25-39.

Fitzgerald, M., and C. J. Woolf (1982) The time course and specificity of the changes in the behavioural and dorsal horn cell responses to noxious stimuli following peripheral nerve capsaicin treatment in the rat. Neuroscience 7: 2051-2056.

Fleischer, E., H. O. Handwerker, and S. Joukhader (1983) Unmyelinated nociceptive afferents in two skin areas of the rat. Brain Res. 267. 81-92.

Gibson, S. J., J. M. Polak, S. R. Blom, I. M. Sabate, P. M. Mulderry, M. A. Ghatei, G. P. McGregor, J. F. B. Morrison, J. S. Kelly, R. M. Evans, and M. G. Rosenfeld (1984) Calcitonin gene-related peptide immunoreactivity in the spinal cord of man and eight other species. J. Neurosci. 4: 3101-3111.

Ilockaday, J. M., and C. W. M. Whitty (1967) Patterns of referred pain in the normal subject. Brain 90:481-496.

Hökfelt, T., O. Johansson, Ȧ. Ljundahl, J. M. Lundberg, and M. Schultzberg (1980) Peptidergic neurons. Nature 287: 515-521.

Hong, K. A., W. Jänig, and R. F. Schmidt (1978) Properties of group IV fibres in the nerves of the knee joint of the cat. J. Physiol. (Lond.) 284: $178-179$.

Jancso, G., E. Kiraly, and A. Jancso-Gabor (1980) Direct evidence 
for an axonal site of action of capsaicin. Naunyn Schmeidebergs Arch. Pharmacol. 313: 91-94.

Jancso, N. (1968) Desensitization with capsaicin and related acylamides as a tool for studying the function of pain receptors. In Pharmacology of Pain, R. K. S. Lim, ed., pp. 33-55, Pergamon, Oxford, U.K.

Lewis, T., and J. H. Kellgren (1939) Observations relating to referred pain, visceromotor reflexes and other associated phenomena. Clin. Sci. 4: 47-71.

Light, A. R., and E. R. Perl (1979) Re-examination of the dorsal root projection to the spinal dorsal horn including observations on the differential termination of coarse and fine fibres. J. Comp. Neurol. 186: $117-132$.

Lynn, B., and S. E. Carpenter (1982) Primary afferent units from hairy skin of the rat hindlimb. Brain Res. 238: 29-43.

Lynn, B., and A. Pini (1984) Effects of direct application of capsaicin on the properties of cutaneous afferent fibres. Pain Suppl. 2: S244.

McLaughlan, E. M., and W. Jänig (1983) The cell bodies of origin of sympathetic and sensory axons in some skin and muscle nerves of the cat hindlimb. J. Comp. Neurol. 214: 115-130.

McMahon, S. B., and P. D. Wall (1985) The distribution and central termination of single cutaneous and muscle unmyelinated fibres in rat spinal cord. Brain Res. 359: 39-48.

McMahon, S. B., E. Sykova, P. D. Wall, C. J. Woolf, and S. J. Gibson (1984) Neurogenic extravasation and substance $P$ levels are low in muscle compared to skin in the rat hindlimb. Neurosci. Lett. 52:235240.

Mendell, L. M. (1984) Modifiability of spinal synapses. Physiol. Rev. 64: $260-324$.

Mense, S., and H. Meyer (1985) Different types of slowly conducting afferent units in cat skeletal muscle and tendon. J. Physiol. (Lond.) 363: 403-417.

Mense, S., and M. Stahnke (1983) Responses in muscle afferent fibres of slow conduction velocity to contractions and ischaemia in the cat. J. Physiol. (Lond.) 342: 383-397.

Nagy, J. I., and S. P. Hunt (1982) Fluoride-resistant acid phosphatasecontaining neurones in dorsal root ganglia are separate from those containing substance $P$ or somatostatin. Neuroscience 7: 89-97.

Schiable, H. G., and R. F. Schmidt (1985) Coding of pain information from joints. In Development, Organization and Processing in Somatosensory Pathways, M. Rowe and W. D. Willis, eds., pp. 309316, Liss, New York.

Swett, J. E. (1983) Few C fibres from muscle terminate in lamina II of the spinal cord of the cat. J. Physiol. (Lond.) 345: 157.

Swett, J., and C. J. Woolf (1985) The somatotopic organization of primary afferent terminals in the superficial laminae of the dorsal horn of the rat spinal cord. J. Comp. Neurol. 231: 66-77.

Urban, L., and M. Randic (1984) Slow excitatory transmission in rat dorsal horn: Possible mediation by peptides. Brain Res. 290: 336342 .

Wall, P. D., and M. Fitzgerald (1981) Effects of capsaicin applied locally to adult peripheral nerve. I. Physiology of peripheral nerve and spinal cord. Pain 11:363-377.

Wall, P. D., and C. J. Woolf (1984) Muscle but not cutaneous C-afferent input produces prolonged increases in the excitability of the flexion reflex in the rat. J. Physiol. (Lond.) 356: 443-458.

Wall, P. D., and C. J. Woolf (1985) Noxious stimulus evoked increases in the excitability of the flexor reflex. J. Physiol. (Lond.) 369: 28P.

Willis, W. D., and Coggeshall, R. E. (1978) Sensory Mechanisms of the Spinal Cord. Plenum, New York.

Woolf, C. J. (1983a) Evidence for a central component of post-injury pain hypersensitivity. Nature 306: 686-688.

Woolf, C. J. (1983b) C-primary afferent fibre mediated inhibitions in the dorsal horn of the decerebrate-spinal rat. Exp. Brain Res. 51:283290.

Woolf, C. J., and M. Fitzgerald (1983) The properties of neurones recorded in the superficial dorsal horn of the rat spinal cord. J. Comp. Neurol. 221: 313-328.

Woolf, C. J., and J. E. Swett (1984) The cutaneous contribution to the hamstring flexor reflex in the rat: An electrophysiological and anatomical study. Brain Res. 303: 299-312.

Woolf, C. J., and P. D. Wall (1982) Chronic peripheral nerve section diminishes the primary afferent A-fibre mediated inhibition of rat dorsal horn neurones. Brain Res. 242: 77-85.

Woolf, C. J., and Z. Wiesenfeld-Hallin (1985) Substance P and calcitonin gene related peptide synergistically modulate the excitability of the spinal cord. Neurosci. Lett. Suppl. 22: S239. 